\title{
A growing care gap? The supply of unpaid care for older people by their adult children in England to 2032
}

\author{
LINDA PICKARD*
}

\begin{abstract}
A key feature of population ageing in Europe and other more economically developed countries is the projected unprecedented rise in need for long-term care in the next two decades. There is, however, considerable uncertainty over the future supply of unpaid care for older people by their adult children. The future of family care is particularly important in countries planning to reform their long-term care systems, as is the case in England. This article makes new projections of the supply of intense unpaid care for parents aged $6_{5}$ and over in England to 2032, and compares these projections with existing projections of demand for unpaid care by older people with disabilities from their children. The results show that the supply of unpaid care to older people with disabilities by their adult children in England is unlikely to keep pace with demand in future. By 2032, there is projected to be a shortfall of 160 ,ooo care-givers in England. Demand for unpaid care will begin to exceed supply by 2017 and the unpaid 'care gap' will grow rapidly from then onwards. The article concludes by examining how far this unpaid 'care gap' is likely to be met by other sources of unpaid care or by developments in new technology and examines the implications of the findings for long-term care policy.
\end{abstract}

KEY WORDS - unpaid care, intergenerational care, older people, long-term care policy, England, projections.

\section{Introduction}

As the numbers of older people increase in an unprecedented manner in Europe and other more economically developed countries in the coming years, demand for long-term care is also likely to increase substantially (Colombo et al. $2011 a$ : 1). In many European countries, such as England, the long-term care system relies heavily on unpaid or informal care from families or friends (Kraus et al. 2011). In these countries, the increase

* London School of Economics \& Political Science - LSE Health and Social Care, London, UK. 
in demand for long-term care is also likely to mean an increase in demand for unpaid care. Yet there are concerns about the future supply of unpaid care (Colombo et al. 2011 a). If the supply of unpaid care does not meet rising needs for care, then this could lead to an increase in demand for formal long-term care. The issue of the supply of unpaid care to older people is, therefore, of increasing importance for long-term care policy and poses 'multifarious challenges' for welfare states in Europe and elsewhere (Geerts et al. 2012).

Most unpaid care for older people is provided either by their children or by their spouses or partners. In England, approximately 1.4 million older people with disabilities living in their own homes currently receive unpaid care and, of these, approximately 85 per cent receive care from either an adult child or spouse (Pickard et al. 2012). Of those receiving care from a child or spouse, slightly more currently receive care from a child than a spouse, but the difference is not great.

Trends in care by children and by spouses are likely to be very different in the coming years. It is projected that care by spouses or partners is likely to increase considerably in future, primarily because projected improvements in male mortality are likely to lead to a fall in the number of widows (Gaymu et al. 2008; Office for National Statistics (ONS) 2009). There is, however, considerable uncertainty over the future supply of unpaid care for older people from their adult children. There are two main issues around the supply of intergenerational care for older people. The first relates to the future availability of children to provide unpaid care. Despite falling family sizes and decreasing fertility rates, studies in Europe (including the United Kingdom (UK)) have suggested that there is likely to be a decline in the proportion of people with no surviving child over the next 20 years or so (Gaymu, Ekamper and Beets 2007; Murphy, Martikainen and Pennec 2006). However, these trends are likely to affect women more than men and to vary between countries (Gaymu et al. 2007). The second issue relates to the ability or willingness, the propensity, to provide unpaid care. It is argued that a decline in the rate of intergenerational care provision in future will arise from such factors as the decline in co-residence of older people with their children and the continuing rise in labour market participation by mid-life women (Allen and Perkins 1995; Colombo et al. 2011 ; Grundy 2000; Haberkern et al. 2012).

It is sometimes suggested that the increase in care provided by spouses and partners will compensate for the potential decline in care by children. For example, the Organisation for Economic Co-operation and Development (OECD) report, Help Wanted?, suggests that, even though there may be a shortfall in the supply of care by children to older parents in future, other forms of unpaid care, such as increased care by spouses, could compensate 
for this (Colombo et al. 2011b). A more recent OECD report suggests that 'demographic ageing ... enlarges the potential pool of care providers among the elderly' because older people are 'net providers of support' (Haberkern et al. 2012: 194). However, both these OECD reports acknowledge that there are limits to the extent to which care by spouses or other older people can compensate for a shortfall in the supply of care by children. As Colombo et al. put it, the increase in supply of care is unlikely to compensate fully for the expected decline. Longer-term prospects for European countries remain uncertain' (201 1 b: 66). Haberkern et al., while acknowledging the increased role that older people may play in informal care provision in future, also recognise that the oldest old, aged 85 and over, are 'net receivers' of care (2012: 193). It is among the oldest old that there are projected to be the greatest increases in numbers in the coming decades (Colombo et al. 2011 b).

The uncertainty over the supply of unpaid care is particularly important where countries are planning to reform their long-term care systems in response to population ageing. In England, where reform of the long-term care system has been an issue for the last 15 years or so (Comas-Herrera, Wittenberg and Pickard 2010, 2011), the latest proposals for reform put forward by the Dilnot Commission are currently under consideration by the Government (Commission on Funding of Care and Support (CFCS) 2011; Her Majesty's Government (HMG) 2012). One of the Commission's key criteria for the evaluation of long-term care funding options has been their future sustainability, including their ability to respond to demographic and societal changes. The future supply of unpaid care is a key sociodemographic factor that needs to be taken into account in the development of long-term care policy.

Given the different future trends in intergenerational care and spouse care, it is important to distinguish between care by children and care by spouses in projections of both demand and supply. In England, there are existing projections of demand for unpaid care by people aged $6_{5}$ and over with disabilities to the early 2030s, which distinguish demand for care from spouses/partners and demand for care from children (Pickard et al. 2012). However, there are no projections of the supply of unpaid care that distinguish between care by children and care by spouses. With the exception of an earlier discussion paper (Pickard 2008), existing projections of the supply of unpaid care for older people in the UK do not distinguish between different providers of care (Carers UK 2001; Karlsson et al. 2006; Richards, Wilsdon and Lyons 1996). Karlsson and colleagues, for example, make projections of long-term care for older people in the UK to 2040, modelling demand for formal and informal care and the supply of informal care. Their study finds that, with regard to the older population, 'there will 
be a shortage of informal care for some decades, unless the patterns of provision change' (Karlsson et al. 2006: 202). Given the projected increase in spouse care in the coming decades, it is likely that the shortfall in the provision of unpaid care to older people identified by Karlsson and colleagues is primarily due to a shortfall in care provided by children. However, the extent of the shortfall in the supply of intergenerational care for older people, how soon it is likely to occur and whether patterns of care provision are likely to change, have not been explored.

This article has two main aims. The first is to make projections of the supply of unpaid care specifically by children for their older parents in England to 2032. The second aim is to compare these projections of supply with existing projections of demand for unpaid care by older people from their children in England to 2032, in order to identify how far the supply of care is likely to keep pace with demand. The article presents new projections of the supply of intergenerational care but uses existing projections of demand (Pickard et al. 2012).

The article has three main parts. The first part begins by presenting the methods used for modelling the projections of the supply of unpaid care for older parents. It also provides an account of the modelling of demand for unpaid care, based on Pickard et al. (2012), and describes the methods used to compare projections of supply and demand. The second part of the article presents the results. It first presents projections of the numbers of people providing unpaid care to older parents between 2007 and 2032. It then compares these projections of supply with existing projections of demand for care from children by older people with disabilities. Finally, the article ends with a discussion of the findings and the implications for long-term care policy.

\section{Methods}

\section{Making projections of the supply of unpaid care to parents: introduction}

The projections of the supply of care estimate the numbers of people providing unpaid care for parents ${ }^{1}$ aged $6_{5}$ and over in England between 2007 and 2032 . The base year of 2007 is chosen primarily for comparability with the projections of demand, as described later. The projections draw on information on the propensity to provide care in detailed modules on unpaid care provision contained in the General Household Survey (GHS). These ask respondents whether they 'look after someone who has long-term physical or mental ill health or disability, or problems related to old age' and, if so, for whom they provide care and the age of the caredfor person (Maher and Green 2002: $3^{0}-5$ ). The projections relate 
to unpaid care provision by people aged 30-74, since nearly all unpaid care for older parents is provided by people in this broad age-band (Pickard 2009).

The article is concerned in particular with the supply of intense unpaid care; that is, care provided for 20 or more hours a week to a parent aged $6_{5}$ and over. The focus is on provision of care for 20 or more hours a week partly because care at this level of intensity is more likely to be provided to older people with disabilities than care provided at lower levels of intensity (cf. Kemper 1992), and it is with older people with disabilities that the demand-side projections are concerned.

\section{Making projections of unpaid care provision: factors affecting propensity to care}

In making projections of the numbers of people providing intense unpaid care to older parents in future, the factors likely to affect the provision of this form of unpaid care need to be taken into account. In the present analysis, the factors affecting the provision of intense care to older parents are examined using logistic regression analysis of cross-sectional data from the GHS.

The GHS (subsequently called the General Lifestyle Survey and now part of the Integrated Household Survey) is a multi-purpose continuous survey based each year on a large sample of the general population resident in private households in Great Britain. People aged 16 and over were asked questions on unpaid care provision in 1985, 1990, 1995 and 2000. ${ }^{2}$ The detailed modules of questions on unpaid care provision have not been included in the GHS or its successors since 2000. Nevertheless, the detailed GHS modules on unpaid care remain a good source for the current analysis because they include information about the age of the person cared for, an important consideration in the present context, since the projections are concerned specifically with care for people aged $6_{5}$ and over. Other more recent surveys do not ask about the age of the person cared for, 3 while the 2011 Census includes information on numbers providing unpaid care, but does not ask about the age of the cared-for person or their relationship to the carer. 4

The literature in the UK suggest that age, gender and marital status are all associated with the provision of intense care to older parents (Arber and Ginn 1991; Clarke 1995; Glendinning 1992; Hirst 1999; Parker 1993; Parker and Lawton 1994; Qureshi and Walker 1989). There is also evidence that education and housing tenure affect intense unpaid care provision more generally (Young, Grundy and Kalogirou 2005). A number of other variables may affect the provision of unpaid care to parents, 
such as employment status, health, ethnicity and whether parents are alive (cf. Leontaridi and Bell 2001; Young, Grundy and Kalogirou 2005). However, analytical and data limitations restrict the extent to which some of these variables can be taken into account here. Employment and health may be endogenously related to provision of care and therefore are not usually included in explanatory models of care provision using crosssectional data (Parker and Lawton 1994; Richards, Wilsdon and Lyons 1996).5 The number of people in relevant age groups of the ethnic minority population is too small to allow for consideration of ethnicity as a factor in provision of care using the GHS ( $c f$. Evandrou 200o), while information about whether parents are alive is not available in the GHS. ${ }^{6}$

The logistic regression analysis of the factors affecting provision of intense care for older parents carried out here therefore includes five independent variables: age, gender, marital status, education and housing tenure. Four different models are run, one for each year in which the GHS data were collected. The analysis examines each year separately, partly because the results are subsequently used to inform the analysis of trends over time in provision of care (as explained below). In the analysis, age is broken down into three broad categories (30-44, $45^{-6}$, and $65_{5}$ and over). Marital status is divided into de facto 'married' (those legally married and those co-habiting), and de facto 'single' (those who are single (never married), widowed, divorced, separated and not co-habiting). ${ }^{7}$ Education is divided into three categories: no qualifications, qualifications below degree level and higher educational qualifications. Housing tenure is divided into those who are owner occupiers and those who are tenants. The conventional interpretation that probability values below 0.05 are statistically significant is applied.

The multivariate analysis shows that age, gender and marital status are significantly associated with provision of intense intergenerational care in most or all years (Table 1 ). The probability of providing intense intergenerational care is lower for those aged $3 \mathrm{O}^{-} 44$ and those aged $65^{-74}$ than for those aged $45^{-64}$. The probability of providing intense intergenerational care is higher for women than for men. Married/co-habiting people are less likely to provide care than de facto single people. Controlling for other factors in the models, educational qualifications and housing tenure are not significantly associated with provision of intense care for older parents in any year. The lack of association between provision of intergenerational care and socio-economic variables, controlling for other relevant factors, is consistent with other research carried out in Britain during this period, which found few differences by social class in the prevalence of care to older parents (Arber and Ginn 1993; Glaser and Grundy 2002).

The multivariate analysis therefore suggests that key factors affecting provision of intense intergenerational care for older people include age, 
T А В L E 1. Results (odds ratios) from logistic regression of probability of providing unpaid care to older parents for 20 or more hours a week by people aged 30-69, ${ }^{\mathrm{I}}$ England, I985, I990, I995, 2000

\begin{tabular}{|c|c|c|c|c|}
\hline Characteristics and categories & $\begin{array}{c}1985 \\
\text { (Model 1) }\end{array}$ & $\begin{array}{c}1990 \\
(\text { Model 2) }\end{array}$ & $\begin{array}{c}1995 \\
\text { (Model } 3 \text { ) }\end{array}$ & $\begin{array}{c}2000 \\
(\text { Model } 4)\end{array}$ \\
\hline & \multicolumn{4}{|c|}{ Odds ratios } \\
\hline \multicolumn{5}{|l|}{ Age group: } \\
\hline $3^{0}-44$ & $0.7 \mathrm{~ns}$ & $0.3^{* * *}$ & $0.3^{* * *}$ & $0.4^{* * * *}$ \\
\hline $45^{-64}$ & 1.0 & 1.0 & 1.0 & 1.0 \\
\hline $65-69$ & $0.6 \mathrm{~ns}$ & $0.4^{* *}$ & $0.4^{* *}$ & $0.7 \mathrm{~ns}$ \\
\hline \multicolumn{5}{|l|}{ Gender: } \\
\hline Men & 1.0 & 1.0 & 1.0 & 1.0 \\
\hline Women & $1.6^{* *}$ & $1.7^{* *}$ & $2.7^{* * * *}$ & $1.9^{* *}$ \\
\hline \multicolumn{5}{|l|}{ Marital status: } \\
\hline De facto single & 1.0 & 1.0 & 1.0 & 1.0 \\
\hline Married or co-habiting & $0.6 * *$ & $0.4^{* * * *}$ & $0.8 \mathrm{~ns}$ & $0.5^{* *}$ \\
\hline \multicolumn{5}{|l|}{ Education: } \\
\hline No qualifications & 1.0 & 1.0 & 1.0 & 1.0 \\
\hline Qualifications below degree level & $0.9 \mathrm{~ns}$ & $1.1 \mathrm{~ns}$ & $1.1 \mathrm{~ns}$ & $1.1 \mathrm{~ns}$ \\
\hline Higher educational qualifications & $0.7 \mathrm{~ns}$ & $1.0 \mathrm{~ns}$ & $0.8 \mathrm{~ns}$ & $0.6 \mathrm{~ns}$ \\
\hline \multicolumn{5}{|l|}{ Housing tenure: } \\
\hline Owner-occupier & 1.0 & 1.0 & 1.0 & 1.0 \\
\hline Tenant & $0.9 \mathrm{~ns}$ & $1.1 \mathrm{~ns}$ & $0.9 \mathrm{~ns}$ & $0.7 \mathrm{~ns}$ \\
\hline
\end{tabular}

Notes: 1 . The General Household Survey does not include information on education for people aged 70 and over, so the results are for people aged $30-69$. Unweighted sample numbers of respondents aged 3o-69 in England are: 9,653 (1985); 9,325 (1990); 9,553 (1995) and 8,130 (2000).

Significance levels: $* * p<0.01, * * * p<0.001$, ns: not significant.

Sources: General Household Survey for 1985, 1990, 1995 and 2000.

gender and marital status. Therefore, these factors need to be included in the modelling of provision of this form of care in future years.

\section{Making projections of unpaid care provision: trends in propensity to provide care}

The projections of the numbers of people providing unpaid care also need to be based on assumptions about the propensity to provide care in future. In the present article, these assumptions about the propensity to provide care are based on empirical analysis of recent past trends in unpaid care provision. The analysis uses the GHS data between 1985 and 2000 to examine trends over time in the provision of care to parents for 20 or more hours a week by those aged $3 \mathrm{O}^{-} 74$. Initial bivariate analysis shows that there was little difference over time in the percentage of people aged $3 \mathrm{O}^{-} 74$ providing care to older parents in England between $198_{5}$ and 2000. 
The percentages range from 1.4 to 1.6 per cent, with 95 per cent confidence intervals ranging from 1.2 to 1.9 per cent (Pickard 2008).

Further analysis was then undertaken to examine trends over time controlling for key socio-demographic variables, using multivariate analysis. Four different logistic regression models are examined, each concerned with a different time period (1985/1990, 1990/1995, 1995/2000 and $1985 / 2000)$. The factors included in the analysis are those identified in Table 1 as significant in the provision of intense unpaid care to parents in either of the years in the comparison, which in effect means that the models all include age, gender and marital status. The results show that, controlling for key socio-demographic factors, there were no significant changes in the probability of providing intense intergenerational care to older parents during any of the time periods examined between 1985 and 2000 (Table 2 ). The absence of change in provision of intense unpaid care to older parents during this period is somewhat surprising, given that previous studies have identified an intensification of caring at this time, and the trends identified here are discussed further at the end of the article. In terms of the methods used in the projections, because there is no evidence of change in the provision of intense unpaid care to parents in the recent past, the assumption is made that there will be no change in the propensity to provide intense unpaid care to older parents in future.

\section{Making projections of unpaid care provision: probability of providing unpaid care}

Given the assumption of a steady state with regard to the propensity to provide unpaid care, the projected numbers of care-givers in future years are based on the proportions of people providing unpaid care at present. In order to establish the current prevalence of unpaid care provision, the 2000 GHS is utilised. Table 3 shows the percentages of de facto single and married men and women, by age, providing intense unpaid care to older parents. It is these percentages that are taken into account in the subsequent modelling. ${ }^{8}$ The table shows that, controlling for age and marital status, women are more likely to provide unpaid care than men, with the exception that single men in mid-life and older age groups have higher rates of provision of care than single women, in a relationship that has been well described in the literature (Arber and Ginn 1991).

\section{Making projections of unpaid care provision: projecting the numbers providing care}

The numbers of people providing unpaid care for 20 or more hours a week to older parents are projected using a macro-simulation (aggregate) model 
T A B L E 2. Results (odds ratios) from logistic regression of probability of providing care to older parents for 20 or more hours a week by people aged $30-74$ over four time periods between 1985 and 2000, England

\begin{tabular}{|c|c|c|c|c|}
\hline Characteristics and categories & $\begin{array}{c}1985 / 1990 \\
(\text { Model 1) }\end{array}$ & $\begin{array}{c}1990 / 1995 \\
\text { (Model 2) }\end{array}$ & $\begin{array}{c}\text { 1995/200o } \\
\text { (Model 3) }\end{array}$ & $\begin{array}{c}1985 / 2000 \\
(\text { Model } 4)\end{array}$ \\
\hline & \multicolumn{4}{|c|}{ Odds ratios } \\
\hline \multicolumn{5}{|l|}{ Age group: } \\
\hline $3^{\mathrm{o}-44}$ & $0.5 * * *$ & $0.3 * * *$ & $0.3^{* * *}$ & $0.6 * * *$ \\
\hline $45^{-64}$ & 1.0 & 1.0 & 1.0 & 1.0 \\
\hline $65-74$ & $0.3^{* * *}$ & $0.3^{* * *}$ & $0.3^{* * *}$ & $0.4^{* * * *}$ \\
\hline \multicolumn{5}{|l|}{ Gender: } \\
\hline Men & 1.0 & 1.0 & 1.0 & 1.0 \\
\hline Women & $1.6 * * *$ & $2.1 * * *$ & $2 \cdot 3^{* * * *}$ & $1.7^{* * * *}$ \\
\hline \multicolumn{5}{|l|}{ Marital status: } \\
\hline Single & 1.0 & 1.0 & 1.0 & 1.0 \\
\hline Married & $0.5^{* *}$ & $0.6 * * *$ & $0.7^{*}$ & o. $6^{* * * *}$ \\
\hline \multicolumn{5}{|l|}{ Time period $(1985 / 1990)$ : } \\
\hline 1985 & 1.0 & $\mathrm{n} / \mathrm{a}$ & $\mathrm{n} / \mathrm{a}$ & $\mathrm{n} / \mathrm{a}$ \\
\hline 1990 & $1.2 \mathrm{~ns}$ & $\mathrm{n} / \mathrm{a}$ & $\mathrm{n} / \mathrm{a}$ & $\mathrm{n} / \mathrm{a}$ \\
\hline \multicolumn{5}{|l|}{ Time period $(1990 / 1995)$ : } \\
\hline 1990 & $\mathrm{n} / \mathrm{a}$ & 1.0 & $\mathrm{n} / \mathrm{a}$ & $\mathrm{n} / \mathrm{a}$ \\
\hline 1995 & $\mathrm{n} / \mathrm{a}$ & $0.8 \mathrm{~ns}$ & $\mathrm{n} / \mathrm{a}$ & $\mathrm{n} / \mathrm{a}$ \\
\hline \multicolumn{5}{|l|}{ Time period (1995/200o): } \\
\hline 1995 & $\mathrm{n} / \mathrm{a}$ & $\mathrm{n} / \mathrm{a}$ & 1.0 & $\mathrm{n} / \mathrm{a}$ \\
\hline 2000 & $\mathrm{n} / \mathrm{a}$ & $\mathrm{n} / \mathrm{a}$ & $1.0 \mathrm{~ns}$ & $\mathrm{n} / \mathrm{a}$ \\
\hline \multicolumn{5}{|l|}{ Time period $(1985 / 2000)$ : } \\
\hline 1985 & $\mathrm{n} / \mathrm{a}$ & $\mathrm{n} / \mathrm{a}$ & $\mathrm{n} / \mathrm{a}$ & 1.0 \\
\hline 2000 & $\mathrm{n} / \mathrm{a}$ & $\mathrm{n} / \mathrm{a}$ & $\mathrm{n} / \mathrm{a}$ & $1.0 \mathrm{~ns}$ \\
\hline
\end{tabular}

Notes: Unweighted sample numbers of respondents aged 30-74 in England are: 10,542 (1985); 10,122 (1990); 10,382 (1995) and 8,755 (2000). n/a: not applicable.

Significance levels: $* p<0.05$, $* * p<0.01, * * * p<0.001$, ns: not significant.

Sources: General Household Survey for 1985, 1990, 1995 and 2000.

of the supply of unpaid care. The percentages providing unpaid care are multiplied by the numbers in the population by age, gender and marital status. The projected numbers of people in the population, by age and gender, are derived from the Government Actuary's Department (GAD) 2006-based population projections (ONS 2008). Because the provision of unpaid care relates to the household population, it is necessary to divide the total projected population into the household and non-household populations. This was achieved using the 2001 Census (Sample of Anonymised Records), on the assumption that the proportion of the population in private households remains constant over time, by age and gender. The projected numbers by age and gender are further broken down by de facto marital status using the GAD 2006-based marital status 
TA B LE 3. Provision of unpaid care to older parents for 20 or more hours a week by people aged 30-74, by age, gender and de facto marital status, England, 2000

\begin{tabular}{|c|c|c|c|c|}
\hline $\begin{array}{l}\text { Gender and } \\
\text { marital status }\end{array}$ & Age & $\begin{array}{l}\text { Percentage } \\
\text { providing } \\
\text { unpaid care }\end{array}$ & $\begin{array}{l}\text { Weighted } \\
\text { sample base } \\
\text { (thousands) }\end{array}$ & $\begin{array}{l}\text { Unweighted } \\
\text { sample base }\end{array}$ \\
\hline \multicolumn{5}{|l|}{ Men: } \\
\hline \multirow[t]{3}{*}{ Single } & $3^{0}-44$ & 1.3 & 1,534 & 368 \\
\hline & $45^{-64}$ & 4.1 & 1,212 & $35^{6}$ \\
\hline & $65^{-74}$ & 0.8 & 394 & 139 \\
\hline \multirow[t]{3}{*}{ Married/co-habiting } & $3^{0}-44$ & 0.1 & 3,836 & 1,215 \\
\hline & $45^{-64}$ & 0.9 & 4,172 & $1,54^{2}$ \\
\hline & $65^{-74}$ & 0.9 & 1,411 & $5^{27}$ \\
\hline \multicolumn{5}{|l|}{ Women: } \\
\hline \multirow[t]{3}{*}{ Single } & $3^{0}-44$ & 1.8 & 1,406 & 497 \\
\hline & $45^{-64}$ & 2.3 & 1,401 & $4^{80}$ \\
\hline & $65^{-74}$ & 0.3 & 893 & 291 \\
\hline \multirow[t]{3}{*}{ Married/co-habiting } & $3^{0}-44$ & 1.1 & 4,067 & 1,369 \\
\hline & $45^{-64}$ & 2.7 & 4,266 & $1,55^{2}$ \\
\hline & $65^{-74}$ & 1.6 & $1,15^{6}$ & $4^{19}$ \\
\hline All men & $3^{0-}-74$ & 1.0 & 12,559 & 4,147 \\
\hline All women & $3^{0}-74$ & 1.8 & 13,189 & 4,608 \\
\hline All men and women & $3^{0}-74$ & 1.4 & 25,748 & 8,755 \\
\hline
\end{tabular}

Source: General Household Survey for 2000.

and co-habitation projections (ONS 2009).9 As already indicated, the projections of unpaid care provision assume that the probability of providing unpaid care for 20 or more hours a week to an older parent by age, gender and marital status in England remains unchanged, as reported in the 2 OOOO GHS.

\section{Making projections of demand for unpaid care}

The information on demand for unpaid care is drawn from published estimates of the numbers of older people with disabilities projected to receive unpaid care from their children in England between 2007 and 2032 (Pickard et al. 2012). These projections are based on a study by the Personal Social Services Research Unit (PSSRU), which makes macro-simulation (aggregate) projections of demand for long-term care for older people aged 65 and over in England (Malley et al. 2011:43-7; Wittenberg et al. 2001: 6-8, 2006: $4-7$ ). It is important to note that the projections of demand are contingent on the availability of key kin and take into account the availability of spouses and adult children. An overview of the modelling 
of demand for unpaid care is given here, with further details in Pickard et al. (2012: 534-8).

The projections of demand for unpaid care begin with the projected numbers of older people with functional disabilities in private households in England, derived from the PSSRU model. The initial part of the model makes projections of estimated numbers of people aged $6_{5}$ and over by age, gender, disability and marital status (Wittenberg et al. 200 1, 2006). Disability is defined in terms of an inability to perform instrumental activities of daily living (IADLs) without help or difficulty performing, or an inability to perform activities of daily living (ADLs) without help. Marital status is defined in terms of de facto marital status. For the purposes of the projections of the availability of children (described below), the de facto single group are further divided by legal marital status. The projections to 2032 are based on GAD's 20o6-based population and marital status/co-habitation projections. The projections assume that age/gender-specific disability rates remain unchanged, based on analysis of the 2001-2 GHS.

Projections of the percentages of older people aged 75 and over with and without living children, by age, gender and marital status, are derived from published FELICIE data (Gaymu et al. 2008). The FELICIE projections of childlessness in the population aged 75 and over are supplemented by projections for the population aged $65^{-74}$, based on data from Waves 1 and 3 of the English Longitudinal Study of Ageing (ELSA) (Pickard et al. 2012).

The availability of kin is a major factor affecting household type and, in turn, household type is closely associated with unpaid care receipt. The household type projections in the model of demand for unpaid care take into account age, gender, marital status, disability and the availability of children. The distributions of older people into different household types by these factors are derived from Wave 1 of ELSA, and the household-type distributions are kept constant in future years. Projections of unpaid care receipt are based on current receipt of unpaid care by older people, using Wave 1 ELSA data. Unpaid care is defined as help with personal care or domestic tasks from relatives or friends, provided because of the disability of the care-recipient. The factors incorporated into the projections of unpaid care receipt by older people with disabilities are age, gender, legal marital status (for de facto single people), housing tenure and household type. It is assumed that the proportions of older people receiving unpaid care remain constant over time. The analysis therefore implicitly assumes that, contingent on the availability of key kin, the supply of unpaid care rises in line with demand. Sources of unpaid care are distinguished using Wave 1 ELSA data. Three principal sources are identified: spouses, children and others. The projections assume that the propensity, within household types, to receive care from each source remains constant over time. 


\section{Methods for comparing projections of unpaid care supply and demand}

The projected numbers of people providing unpaid care to older parents are compared to the numbers of older people with disabilities projected to need, or 'demand', unpaid care from their adult children in future years. As far as possible the projections of supply and demand share the same assumptions. The projections of supply and demand are both based on GAD 20o6-based population and marital status/co-habitation projections; both assume no change in the long-term care system in England; and both relate to England between 2007 and 2032 .

In comparing the projections of supply and demand, the numbers of people projected to provide intense unpaid care for 20 or more hours a week to older parents ('care-providers') are compared with the numbers of older people with disabilities projected to receive care from their children ('carereceivers'). The numbers needing care are likely to exceed the numbers providing it, even in the base year. This is because, although most care provided for 20 or more hours a week to parents is likely to be provided to someone with a disability, not all older people with disabilities receive care for long hours. Disability is defined in the PSSRU model in terms of difficulty with, or an inability to perform, domestic tasks or personal care tasks. Older people unable to perform domestic tasks, for example, include those unable to do their shopping, a task that is unlikely to take 20 hours a week to perform. Nevertheless, the ratio of care-receivers to care-givers is a measure which, as shown later, can be used to examine the extent to which the supply of unpaid care keeps pace with demand over time.

\section{Results}

Projections of supply of intense unpaid care to older parents, 2007-2032

In the base year (2007), there were approximately 400,ooo people providing care for 20 or more hours a week to older parents in England (Table 4). Of these, approximately $6_{5}$ per cent were women, with over a quarter of a million women providing intense intergenerational care, compared to around 140,000 men. Over 9o per cent of those providing intense care to parents were under the age of 65 , with approximately 360 ,ooo men and women aged 3o-64 providing this form of care. Although the probability of providing care is higher for single than married/co-habiting people, the number of married/co-habiting people providing care exceeded those who are single because of the underlying preponderance of married/co-habiting people in the age groups most likely to provide care.

Assuming constant probabilities of providing care by age, gender and marital status, the numbers of people providing care to older parents 
T А В L E 4. Estimated numbers of people providing care to older parents for 20 or more hours a week by people aged 3O-74, England, 2000-2032

\begin{tabular}{|c|c|c|c|c|c|c|c|c|}
\hline & \multicolumn{3}{|c|}{ Age } & \multicolumn{2}{|c|}{ Gender } & \multicolumn{2}{|c|}{ Marital status } & \multirow[b]{2}{*}{ Total } \\
\hline & $3^{0}-44$ & $45^{-64}$ & $65^{-74}$ & Men & Women & Single & $\begin{array}{l}\text { Married/ } \\
\text { co-habiting }\end{array}$ & \\
\hline & \multicolumn{8}{|c|}{ Estimated numbers (in thousands) } \\
\hline 2007 & 100 & 265 & 40 & 140 & 260 & $15^{0}$ & 255 & 400 \\
\hline 2012 & 100 & 280 & $5^{\circ}$ & 155 & 270 & 165 & 260 & 430 \\
\hline 2017 & 100 & 300 & 55 & 170 & 285 & 185 & 265 & $45^{\circ}$ \\
\hline 2022 & 110 & 305 & 55 & 175 & 290 & 200 & 265 & $4^{6} 5$ \\
\hline 2027 & 115 & 305 & 60 & 185 & 295 & 210 & 265 & 475 \\
\hline 2032 & 110 & 310 & 65 & 190 & 295 & 220 & 265 & $4^{8} 5$ \\
\hline $\begin{array}{l}\% \text { change, } \\
2007-2032\end{array}$ & 14.6 & 18.0 & $5^{0.3}$ & $33 \cdot 7$ & $13 \cdot 4$ & 47.0 & $5 \cdot 0$ & 20.5 \\
\hline
\end{tabular}

Notes: Numbers are rounded to nearest 5,ooo; percentage change is based on un-rounded figures; figures may not add exactly due to rounding.

Sources: 20o6-based official population and marital status/co-habitation projections; 2001 Census (Sample of Anonymised Records); General Household Survey for 2000.

are projected to increase by approximately 20 per cent between 2007 and 2032 (Table 4 ). Numbers are projected to rise from approximately 400 , ooo in 2007 to approximately 485 , ooo in 2032 . The key drivers of the supply of unpaid care to parents in future are the underlying projected changes in the numbers in the population in the relevant age groups and the projected changes in marital status. The projected increase in the numbers of people providing intense unpaid care to parents is largely driven by the increase in the underlying number in the population aged $3 \mathrm{O}-74$, which is projected to rise by 16 per cent by $203^{2}$ (Table 7). The percentage increase in the number of care-givers is projected to be somewhat greater than this, primarily because the number of single people is projected to increase much faster than the number of married/co-habiting people (Table 4 ), and the probability of providing care is greater for single than married people (Table 1).

In many respects, the characteristics of people providing care in 25 or so years' time are projected to be similar to those doing so at present. Although the numbers of people providing care aged $65^{-}-74$ are projected to increase faster than any other age group, nearly go per cent of all those providing intense care will still be under the age of $6_{5}$ in 2032, and therefore they will still be almost wholly of 'working age' (Table 4). Similarly, although the numbers of men are projected to increase faster than the numbers of women, women are still projected to constitute over 6o per cent of those providing care in 2032 . 
T А В L E 5. Estimated numbers of people aged 65 and over with disabilities, by sources of receipt of unpaid care, England, 20OO-2032

\begin{tabular}{lcccccc}
\hline & \multicolumn{5}{c}{ Sources of unpaid care } \\
\cline { 2 - 5 } & None & $\begin{array}{c}\text { Spouse } \\
\text { only }\end{array}$ & $\begin{array}{c}\text { Child } \\
\text { only }\end{array}$ & $\begin{array}{c}\text { Child and } \\
\text { spouse }\end{array}$ & $\begin{array}{c}\text { Other } \\
\text { relatives or } \\
\text { friends }\end{array}$ & $\begin{array}{c}\text { Total receiving } \\
\text { care from child }\end{array}$ \\
\hline & & & Estimated numbers (in thousands) & \\
2007 & 740 & 500 & 530 & 145 & 200 & 675 \\
2012 & 795 & 590 & 545 & 170 & 205 & 715 \\
2017 & 890 & 685 & 585 & 200 & 220 & 785 \\
2022 & 995 & 775 & 645 & 220 & 245 & 865 \\
2027 & 1,120 & 865 & 720 & $25^{\circ}$ & 290 & 970 \\
2032 & 1,265 & 960 & 810 & 275 & 340 & 1,080 \\
$\%$ change, & 71.5 & 91.8 & 52.2 & 90.4 & 68.2 & 60.4 \\
$2007-2032$ & & & & & & \\
\hline
\end{tabular}

Notes: Total receiving care from child includes care from child only and care from child and spouse. Numbers are rounded to nearest 5, ooo. Percentage change is based on un-rounded figures. Figures may not add exactly due to rounding.

Source: Pickard et al. (2012).

In summary, assuming constant probabilities by age, gender and marital status, the projections show a moderate increase in the numbers of people providing care for 20 or more hours a week to parents between 2007 and 2032. The overwhelming majority of those providing intense care to parents in the early 203 os are still likely to be of 'working age', and women are still projected to outnumber men by nearly two to one.

Projections of demand for unpaid care by disabled older people from children, 2007-2032

The numbers of older people aged $6_{5}$ and over with disabilities who are projected to receive, or 'demand', care from a child will increase in England by approximately $5^{\mathrm{O}}$ per cent between 2007 and 2032 (Table 5 ). The projected increase in receipt of care from a child is lower than the projected increase in receipt of care from a spouse or partner. Numbers of older people with disabilities receiving care from a spouse/partner are projected to increase by over 90 per cent between 2007 and 2032. The total numbers of disabled older people receiving care from children, including those receiving care from a child only and those receiving care from both a child and spouse, are projected to rise by approximately 6o per cent over the next 25 years or so.

These trends in demand for unpaid care are driven, first of all, by the projected increase in the numbers of older people with disabilities. 
The numbers of people aged $6_{5}$ and over with disabilities are projected to increase by 72 per cent between 2007 and 2032 (Pickard et al. 2012). Sources of unpaid care are, in addition, projected to change over time in response to changes in the availability of kin. The projected increase in 'spouse care' is greater than the increase in care from children partly because married/co-habiting older people are projected to increase faster than de facto single older people. Moreover, the projected increase in the numbers of disabled older people without a child is greater than the increase in the numbers with a child and this also has the effect of reducing demand for care from children in the model (Pickard et al. 2012). ${ }^{10}$

Nevertheless, children are still projected to be an important source of care for older people with disabilities in future. The total numbers of older people with disabilities receiving care from children are projected to rise from approximately 675 , 000 in 2007 to over a million in 2032 (Table 5 ). The underlying reason for the increase in demand for care from children is the sharp rise in the numbers of older old people, aged 75 and over, who are projected to increase by 85 per cent between 2007 and 2032 (Pickard et al. 2012). The majority of older old people are currently single and this will still be the case in 2032 , and care by children is still projected to be the most important source of unpaid care for people aged 75 and over in 2032 (Pickard et al. 2012).

\section{Comparison of supply of unpaid care to parents with demand for care from children}

The projected numbers of people supplying unpaid care to older parents can now be compared to the numbers of older people with disabilities projected to 'demand' unpaid care from their adult children in future (Table 6). In making the comparison between supply and demand, the demand side is assumed to include both older people receiving care from a child only and older people receiving care from both a child and spouse. The rationale for this is that, since the supply-side takes into account all care provided by children to their older parents, irrespective of care provided by spouses, it seems appropriate that the demand-side should also include all care received by older people from their children, irrespective of care received from spouses. The results show that there are currently approximately 675 ,ooo disabled older people receiving unpaid care from their children and approximately 400,00o people providing intense unpaid care for older parents (Table 6). More older people with disabilities therefore receive care from a child than there are children providing care for 20 or more hours a week to older parents. As discussed earlier, the main reason for this is that not all older people with disabilities receive care 
T А в L E 6. Supply of unpaid care provided by adult children for 20 or more hours a week to their older parents ('care-providers') compared to demand for unpaid care by older people with disabilities from their children ('care-receivers'), England, 2007-2032

\begin{tabular}{|c|c|c|c|c|c|}
\hline & $\begin{array}{c}\text { (A) } \\
\text { Care- } \\
\text { providers }\end{array}$ & $\begin{array}{l}(\mathrm{B}) \\
\text { Care- } \\
\text { receivers }\end{array}$ & $\begin{array}{l}(\mathrm{C}) \\
\text { Ratio of care- } \\
\text { receivers to care- } \\
\text { providers }\end{array}$ & $\begin{array}{l}(\mathrm{D}) \\
\text { Care-providers if } \\
\text { supply meets } \\
\text { demand }\end{array}$ & $\begin{array}{c}(\mathrm{E}) \\
\text { 'Care gap' }\end{array}$ \\
\hline & \multicolumn{5}{|c|}{ Estimated numbers (in thousands) } \\
\hline 2007 & 400 & 675 & o.6 & 400 & $\mathrm{o}$ \\
\hline 2012 & $43^{\circ}$ & 715 & 0.6 & 425 & $-<5$ \\
\hline 2017 & $45^{\circ}$ & 785 & o.6 & $4^{65}$ & 15 \\
\hline 2022 & $4^{6} 5$ & 865 & 0.5 & $5^{15}$ & $5^{\circ}$ \\
\hline 2027 & 475 & 970 & 0.5 & $5^{80}$ & 105 \\
\hline 2032 & $4^{8} 5$ & 1,080 & 0.4 & 645 & 160 \\
\hline $\begin{array}{l}\% \text { change, } \\
2007-2032\end{array}$ & 20.5 & 60.4 & $-24 \cdot 9$ & 60.4 & - \\
\hline
\end{tabular}

Notes: Column A is derived from final column of Table 4 and shows projected number of careproviders if propensity to provide care stays constant. Column B is derived from final column of Table 5 and shows projected numbers of older people with disabilities receiving care from either a child or a child and spouse. Column C is column A divided by column B. Column D shows the projected number of care-providers at constant (2007) ratio of care-providers to care-receivers. Column E is difference between columns D and A. Numbers are rounded to nearest 5, 000 . Percentage change is based on un-rounded figures.

Sources: Tables 4 and 5 .

for 20 or more hours a week. The current ratio of older people with disabilities receiving care from a child (care-receivers) to children providing intense care to older parents (care-providers) is approximately 1 to o.6.

The projections suggest that the supply of intense unpaid care by adult children to their older parents is unlikely to keep pace with demand between 2007 and 2032 (Table 6; Figure 1). Assuming no change in the probability of providing unpaid care over time, the numbers of people providing intense care to their older parents are projected to increase by approximately 20 per cent between 2007 and 2032, whereas the numbers of older people with disabilities receiving care from a child, under the assumptions described earlier, are projected to increase by approximately 6o per cent over the same period. The ratio of care-receivers to care-providers is projected to fall by approximately a quarter over the next 25 years or so.

Table 6 also shows the numbers of care-providers that would be needed if the supply of unpaid care were to meet demand in future. This is calculated by assuming that the current (2007) ratio of care-providers to care-receivers remains constant. In other words, the assumption is made that the ratio of care-providers to care-receivers between 2007 and 2032 remains at 0.6 


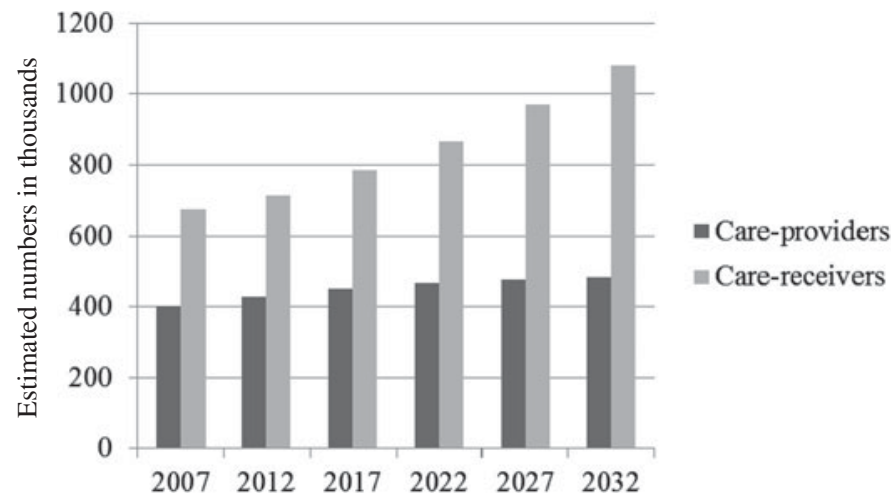

Figure 1. Supply of unpaid care provided by adult children for 20 or more hours a week to their older parents ('care-providers') and demand for unpaid care by older people with disabilities from their children ('care-receivers'), England, 2007-2032. Source: Table 6.

in England. The results show that, if the supply of unpaid care were to meet demand, then the numbers of care-providers would need to increase from approximately 400,000 in 2007 to 645 ,ooo by 2032 (Table 6, column D). The projected numbers of care-providers that would be needed if supply were to meet demand (Table 6, column D) can be compared to the projected numbers of care-providers that are likely to be available, based on the assumption that the probability of providing care remains constant over time at current rates (Table 6, column A). The projected numbers of careproviders, based on constant probabilities of providing care, are lower in 2032 than the numbers that would be needed if supply is to meet demand. Thus, there are projected to be approximately 485 , ooo care-providers in 2032, but the numbers needed if supply is to meet demand would be approximately 645 ,ooo (Table 6 , columns $\mathrm{A}$ and $\mathrm{D}$ ).

Therefore, by 2032 the 'care gap' between the numbers of care-providers projected to be available and the numbers needed to meet demand for care from children amounts to approximately 160,000 care-providers in England (Table 6, column E). This 'care gap' is illustrated in Figure 2, which shows the numbers of care-providers at constant probabilities of providing care and the numbers if supply were to meet demand for care between 2007 and 2032. As the figure illustrates, the 'care gap' begins between 2012 and 2017 and grows rapidly from then onwards.

If demand for unpaid care by older people with disabilities from their children is to be met by intense unpaid care provided by children, at the same rate as at present, then a number of important consequences follow. First, the probability of providing intense unpaid care to parents would need to increase. Table 7 suggests that, if supply were to keep pace with demand, 


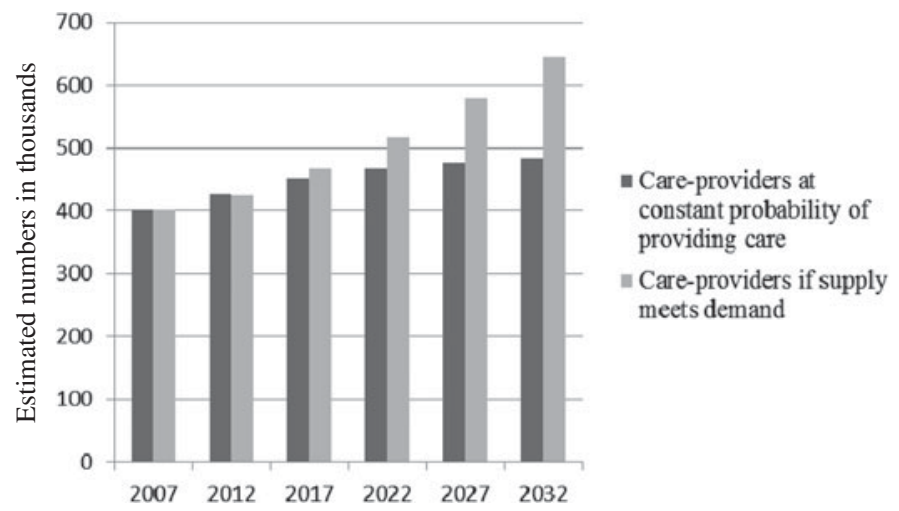

Figure 2. The unpaid 'care gap': care-providers providing intense unpaid care to older parents at constant probabilities of providing care, and care-providers if supply meets demand, England, 2007-2032. Source: Table 6.

the probability of providing intense care to older parents would need to increase by nearly 40 per cent over the next 25 years or so, from approximately 1.4 per cent of those aged $30-74$ in 2007 to 2.0 per cent in 2032 (Table 7, column C). In other words, if patterns of care for older people with disabilities remain constant in future years (an assumption of the demand-side projections), then the probability of providing intense care to older parents would need to rise. Indeed, the probability of providing this form of care would need to be higher than it was during any of the years for which data were available between 1985 and 2000 when, as indicated earlier, the maximum probability of providing care was 1.6 per cent, with an upper confidence interval of 1.9 per cent.

Moreover, given that around 9o per cent of those providing intense care to parents are under the age of 65 , then if supply were to keep pace with demand, it would have important implications for the numbers of people of 'working age' who provide unpaid care. Table 7 suggests that the numbers of people aged $30-64$ who provide intense care to parents, under constant probabilities of care provision, are likely to rise to around 420 ,ooo by 2032 (Table 7 , column D). However, if the supply of care were to keep pace with demand, then this figure would need to be 560 ,ooo in 2032 (Table 7 , column F). The numbers of people under the age of $6_{5}$ who provide intense care to older parents would need to increase by over 40 per cent between 2007 and 2032 if supply were to keep pace with demand, compared to an increase of 16 per cent if the probability of providing care remains constant. Compared to the present time, there would need to be a further 200,000 'working age' people providing care to older parents by 2032, if supply were to meet demand. 
T А В L E 7. Consequences for care-providers if supply of intergenerational care meets demand: propensity to provide care and numbers of 'working-age' care-providers, England, 2007-2032

\begin{tabular}{|c|c|c|c|c|c|c|}
\hline & \multicolumn{3}{|c|}{ Propensity to provide care } & \multicolumn{3}{|c|}{ Numbers of care-providers aged $30-64$} \\
\hline & $\begin{array}{l}\text { (A) } \\
\text { Care- } \\
\text { providers } \\
\text { if supply } \\
\text { meets } \\
\text { demand }^{1}\end{array}$ & $\begin{array}{c}\text { (B) } \\
\text { Total } \\
\text { 3o-74 } \\
\text { year } \\
\text { olds }^{1}\end{array}$ & $\begin{array}{c}(\mathrm{C}) \\
\text { Percentage } \\
\text { providing } \\
\text { care if } \\
\text { supply meets } \\
\text { demand }\end{array}$ & $\begin{array}{c}(\mathrm{D}) \\
\text { Care-providers } \\
\text { aged } 30-64 \text { at } \\
\text { constant } \\
\text { probability of } \\
\text { providing care }\end{array}$ & $\begin{array}{c}(\mathrm{E}) \\
\text { Percentage } \\
\text { of care- } \\
\text { providers } \\
\text { aged } 30-64\end{array}$ & $\begin{array}{c}(\mathrm{F}) \\
\text { Care- } \\
\text { providers } \\
\text { aged } 3 \mathrm{O}^{-} \\
64 \\
\text { if supply } \\
\text { meets } \\
\text { demand }^{1}\end{array}$ \\
\hline 2007 & 400 & 27,780 & 1.4 & 360 & 89.6 & $3^{60}$ \\
\hline 2012 & 425 & 28,710 & 1.5 & 380 & 88.6 & 380 \\
\hline 2017 & $46_{5}$ & 29,970 & 1.6 & 400 & 87.9 & 410 \\
\hline 2022 & $5^{15}$ & 30,970 & 1.7 & $4^{1} 5$ & 88.4 & 455 \\
\hline 2027 & $5^{80}$ & 31,675 & 1.8 & 420 & 88.1 & 510 \\
\hline 2032 & 645 & 32,235 & 2.0 & 420 & 87.0 & $5^{60}$ \\
\hline $\begin{array}{l}\% \text { change, } \\
2007-2032\end{array}$ & 60.4 & 16.0 & 38.2 & 16.4 & -1.71 & $4^{1 \cdot 3}$ \\
\hline
\end{tabular}

Notes: 1. Estimated numbers (in thousands, rounded to nearest 5,000 ). Percentages are based on un-rounded figures. Column A is from Table 6 (column D). Column C expresses column A as a percentage of column B. Columns D and $\mathrm{E}$ are from Table 4 . Column F multiplies column $\mathrm{E}$ by column A.

Sources: Tables 4 and 6.

\section{Discussion and conclusion}

The key finding of this article is that, on the assumptions used here, the supply of intense unpaid care to older people with disabilities by their adult children in England is unlikely to keep pace with demand in future years. Demand for unpaid care by older people with disabilities is projected to exceed supply by 2017 , with the 'care gap' widening over the ensuing years. By 2032, the gap between the numbers of people projected to provide unpaid care and the numbers needed to provide care if demand is to be met amounts to approximately 160 ,ooo care-providers.

A key reason why the supply of unpaid care to older people by their adult children is unlikely to keep pace with demand can be found in underlying demographic trends. An important driver of the care gap is that the numbers of older people, especially the oldest old, are rising faster than the numbers in the younger generation. The care gap is driven by trends well established in the literature on population ageing, in particular the rise in the 'parent support ratio', which measures the numbers of people aged 85 and over relative to those aged $5^{\mathrm{O}-64}$ (United Nations 2002). There is projected 
to be a 'remarkable' increase in the parent support ratio over the coming years in the more economically developed regions of the world, with a trebling of the numbers of people aged 85 and over relative to those aged $5^{\mathrm{O}-64}$ between 2000 and 2050 in the UK (United Nations 2002: 21,458).

What the present article also suggests, however, is that this remarkable anticipated increase in demand for care by older people from the younger generation in the coming years cannot be met without a corresponding increase in the propensity to provide unpaid care by the children of older people. The article has shown that, if intense unpaid care for older parents is to meet demand in the coming decades in England, then the proportion of the population providing this form of care will need to rise. Indeed, the percentages providing this form of care will need to be higher by 2032 than they have ever been in the recent past in England.

Moreover, given that approximately go per cent of those providing intense care to parents are under the age of $6_{5}$, then if supply is to keep pace with demand it would have important implications for the numbers of people of 'working age' providing unpaid care. Currently, approximately 360,000 people aged $30-64$ in England provide unpaid care for older parents for 20 or more hours a week. If supply were to meet demand, then the numbers of 'working age' people providing intense care to older parents would need to rise to approximately 560 ,ooo by $203^{2}$. Such a rise in the numbers of people of working age providing unpaid care is likely to affect equality of opportunities. Given the association between intense unpaid care provision and withdrawal from the labour market (Carmichael, Charles and Hulme 2010; Heitmueller 2007; King and Pickard 2013), a substantial increase in the number of people of working age providing intense unpaid care could lead to a decline in labour market participation, particularly among women, who constitute the majority of care-providers.

The likelihood that the propensity to provide care will increase to meet demand in future is uncertain. The present article has shown that the proportion of people providing unpaid care to older parents has not changed significantly in the recent past in England. Using the GHS, the article has shown that there was no significant change in the provision of unpaid care for 20 or more hours a week to older parents between 1985 and 200o. The trends in unpaid care identified in this article appear somewhat different from the findings of some other studies, which have identified an increase in provision of intense unpaid care in the recent past (Evandrou and Glaser 2002; Hirst 2001; Parker 1998). However, these studies have not been specifically concerned with provision of intense unpaid care to older parents. It is likely that their findings differ from that of the present study either because they do not distinguish between different recipients of care or because they are not concerned specifically with care for older people. 


\section{Linda Pickard}

For example, Evandrou and Glaser (2002) identify an increase in provision of intense care for 20 or more hours a week between 1985 and 2000 using cohort analysis, but their study is concerned with all unpaid care provision, and the increase that they identify could therefore have been due to a rise in provision of care to, for example, spouses/partners. Moreover, the absence of change in the propensity to care specifically for older parents in the recent past, as identified in the present article, is consistent with two contradictory trends described in the literature: a decline in co-residence of older people with their relatives, suggesting a decline in intense co-resident care for parents (Grundy 2000), and an increase in extra-resident care for parents (Hirst 2001).

The lack of change in the provision of intense unpaid care to older parents in the late 2oth century is important because it occurred during a time when there was likely to have been a large increase in demand for care by older parents (Murphy and Grundy 2003). The parent support ratio doubled in the late 2oth century in the UK and, between 1975 and 2000, there was a rise from five to 11 in the number of people aged 85 and over per 100 people aged $5^{\mathrm{O}-64}$ (United Nations 2002: $45^{8}$ ). Therefore, in the recent past, large increases in demand for care do not seem to have resulted in any corresponding increase in the supply of intergenerational care in this country.

It is not necessarily the case that past trends in unpaid care provision will be a guide to future trends. The trends in provision of care during the $1980 \mathrm{~s}$ and 1990 in this country occurred within a specific policy environment that affected the provision of formal services and hence may also have affected the provision of unpaid care. ${ }^{11}$ Moreover, the projections described in this article extend a long way into the future and an important issue is therefore their reliability. The reliability of long-term care projections is often approached through the use of sensitivity analysis, using alternative assumptions to show how sensitive the results are to the assumptions used (Comas-Herrera et al. 20o6; Pickard et al. 2000). Sensitivity analysis carried out on future demand for care shows that it is sensitive to the projected numbers of people aged 85 and over and to future disability rates (Malley et al. 2011; Wittenberg et al. 2001). There is considerable uncertainty about future trends in both these areas. For example, the projections of demand for unpaid care used in the present article assume that disability rates by age and gender remain constant in future, but if there are improvements in the health of the oldest old people and disability rates are lower than those assumed here, then demand for unpaid care would also be lower and the care gap would be smaller. The supply of unpaid care to older parents is also likely to be sensitive to a number of factors, such as rising divorce rates, which may reduce contact between generations 
(Glaser et al. 20o6), and rising labour market participation rates of women and older workers (Colombo et al. 2011 b). For example, if the propensity to provide unpaid care falls in future, due to rising employment rates and the raising of the retirement age, then the supply of unpaid care would be lower than projected here and the care gap would be greater.

As indicated earlier, it has been suggested elsewhere that any shortfall in the provision of unpaid care to parents could perhaps be met by an increase in provision of care by spouses or partners (Colombo et al. 2011 ; Haberkern et al. 2012). However, it is important to note that the projected unpaid care gap presented here allows for an increase in the numbers of older people with spouses/partners. The projections of demand for care are contingent on the availability of key kin, including spouses/partners and children. The projections show that demand for care from spouses is likely to increase much faster than demand for care from children over the next 25 years or so. Nevertheless, the numbers of older people with disabilities who do not have a spouse/partner will also increase by 2032 and hence demand for care from children will increase. This is primarily because of the rise in the numbers of 'older old' people, the majority of whom are currently de facto single, which will still be the case in 2032 .

It is possible that new technologies may help to bridge the unpaid care gap, either by reducing demand for unpaid care or by improving efficiency in the provision of care (Haberkern et al. 2012). For example, monitoring technologies, social alarm systems and care robots can improve the independence of older people and reduce their need for help from other people, while information technology can help care-givers manage care arrangements more effectively. However, it is not clear that technology will be enough to bridge the unpaid care gap because there is as yet insufficient evidence about the impact of new technologies on the provision of unpaid care. The effects of ICT and monitoring technologies on family relations, for example, have not yet been researched (Haberkern et al. 2012). Moreover, the evidence of the impact of telecare for people with social care needs on their informal carers is methodologically weak and the evidence on outcomes for carers is inconsistent (Davies and Newman 2011). Because of the uncertainty surrounding the impact of new technology on unpaid care supply and demand, a European study of long-term care recently concluded that, it is probably wise to anticipate an increasing care burden in European countries and to start making plans to deal with its consequences' (Geerts et al. 2012: 10).

The projected shortfall in unpaid care therefore raises important issues for long-term care policy. If the care gap is to be filled in future then it is likely that more formal services will need to be provided. This suggests that there will need to be a shift from informal to formal care and that long-term 
care systems should seek to reduce reliance on unpaid care in future. In England, this raises serious questions about the recommendations of the Dilnot Commission, which are currently under consideration by the Government (CFCS 2011; HMG 2012). A key recommendation of the Commission is that there should be a cap on the lifetime contribution to adult social care costs that any individual needs to make (CFCS 2011: 5). Where an individual's care costs exceed the cap, the Commission recommends that they should be eligible for full support from the state. However, the Commission's recommendations are particularly reliant on unpaid care. This is because, in the Commission's own words, they are 'carer sighted', which means that they take into account the availability of unpaid care in determining eligibility for publicly funded support (CFCS 2011:52). The Commission's recommendations are, therefore, likely to be particularly susceptible to the projected shortage of unpaid care-providers, identified in this article. A shortage of unpaid care-providers is likely to lead to greater demand for formal services than anticipated by the Commission and an increase in the likelihood of unmet needs for care among vulnerable older people.

If long-term care policy is to reduce reliance on unpaid care, then there needs to be greater use of universal systems of long-term care. Universal longterm care systems determine eligibility primarily on the basis of disability and are likely to be less reliant on unpaid care. In England, a number of proposals for a more universal social care system have been put forward over the last 15 years or so (Comas-Herrera, Wittenberg and Pickard 2010, 2011 ). They include recommendations for free personal care (Royal Commission on Long Term Care 1999) and proposals for a National Care Service (HMG 2010). At least one of these options, that recommended by the Royal Commission on Long Term Care, is explicitly 'carer blind', which means that eligibility for publicly funded care is not dependent on the availability of unpaid care (Royal Commission on Long Term Care 1999: 90). Ultimately, it is only with a 'carer-blind' system that there is likely to be protection in long-term care policy from the 'care gap' identified in this article.

It is recognised that improvements in the design of the model of the supply of unpaid care would be valuable and that further work is needed. It would be valuable to take more factors into account in the projections of unpaid care supply, in particular, the extent to which the younger generation has a living parent. This factor could not be taken into account here because of the lack of information in the GHS data used in the unpaid care supply projections. The new British longitudinal household dataset, Understanding Society, contains data on both unpaid care provision and whether parents are alive, with a very large sample base. However, the data on unpaid care in Understanding Society are limited and, for example, 
do not contain information on the age of the person cared-for, so that analysis of care specifically for older people, of the type undertaken in the present article, could not properly be carried out. Ultimately, our ability to prepare for the future depends on the development of sound, evidencebased policies and, for these, improved data are needed.

\section{Acknowledgements}

This article arises from work undertaken as part of the Modelling Ageing Populations to 2030 (MAP2030) project, funded under a grant from the new Dynamics of Ageing Programme, a cross-research council programme (RES-339-25-0002). Material from the General Household Survey is crown copyright and has been made available via the UK Data Archive. Responsibility for any errors, and all views in this article, lies with the author.

\section{NOTES}

1 Care for older parents includes care for parents-in-law.

2 The sample sizes in the GHS were 18,330 in $1985 ; 17,535$ in $1990 ; 16,745$ in 1995; and 14,124 in 2000.

3 Neither the British Household Panel Survey, Understanding Society or the Family Resources Survey ask about the age of the cared-for person. A question about the age of the cared-for person is asked in the latest Health Survey for England and is planned for Wave 6 of the English Longitudinal Study of Ageing (ELSA), but these data are not yet available. A question about the age of the cared-for person is also included in the 2009-10 Survey of Carers in Households in England, but is not included in the prevalence dataset (Health and Social Care Information Centre 2010).

4 There has been concern that small changes in question wording may have affected the comparability of the GHS data on unpaid care over time, but analysis of the 1985,1990 and 1995 GHS datasets concluded that a more consistent definition of intense caring could be identified (Parker 1998). It is with intense caring that this article is concerned.

5 Although employment, for example, is not included in the modelling reported here, there is a strong association between employment and education. Education is unlikely to be endogenously related to unpaid care provision because educational qualifications tend to be acquired relatively early in the lifecourse, whereas care for parents tends to occur at a later stage.

6 The presence of minor children in the homes of carers was not included here because, when adults enter the ages at which their parents may need care, their own children are likely to have already left home (Soldo 1996). UK research suggests that women's engagement in parent care is not sensitive to whether they have any children or any children under 18 still at home (Agree, Bissett and Rendall 2003).

7 No distinction is made here between married and co-habiting people. There is evidence that provision of intense unpaid care is lower for people who co-habit than those who are married (Pickard 2007), but co-habitation may have more effect on care for spouses than parents. Sample sizes of co-habiting couples at relevant age groups in the GHS are too small for analysis. 
8 The percentages of people providing unpaid care to older parents, used in the projections, are based on weighted sample data from the 2000 GHS, using weights supplied with the dataset (Maher and Green 2002).

9 The projections use the proportions of the population, by age and gender, in the two marital status categories, rather than the absolute numbers projected by GAD. A simplifying assumption is made that, because the proportion of the population aged $3 \mathrm{O}-74$ who are not in the household population is only 1 per cent or less in any age group (by gender), the projected marital status/ co-habitation rates for the whole population equal the marital status/cohabitation rates for the household population.

10 The projected decline in availability of children reported by Pickard et al. (2012) differs from projections by Murphy, Martikainen and Pennec (2006), who identify an increase in availability of children until the mid-203os. The difference arises primarily because the former projections include both men and women, whereas the latter include women only (see Pickard et al. 2012: 541).

11 Indeed, it has been shown elsewhere that the rise in long-stay residential care for older people at this time led to a decline in the most intense forms of unpaid intergenerational care between 1985 and 2000 (Pickard 2012). However, these substitution effects related to care provided for $5^{\circ}$ or more hours a week and there was no evidence of substitution effects in relation to care provided for 20 or more hours a week.

\section{References}

Agree, E., Bissett, B. and Rendall, M.S. 2003. Simultaneous care for parents and care for children among mid-life British women and men. Population Trends, $112,29-35$.

Allen, I. and Perkins, E. (eds) 1995. The Future of Family Care for Older People. HMSO, London.

Arber, S. and Ginn, J. 1991. Gender and Later Life: A Sociological Analysis of Resources and Constraints. Sage, London.

Arber, S. and Ginn, J. 1993. Class, caring and the life course. In Arber, S. and Evandrou, M. (eds), Ageing Independence and the Life Course. Jessica Kingsley Publishers, London, 149-68.

Carers, UK. 2001. It Could Be You. A Report on the Chances of Becoming a Carer. Carers UK, London. Available online at http://www.carersuk.org/professionals/resources/ research-library/item/494-it-could-be-you-a-report-on-the-chances-of-becominga-carer [Accessed June 2013].

Carmichael, F., Charles, S. and Hulme, C. 2010. Who will care? Employment participation and willingness to supply informal care. Journal of Health Economics, 29, 1, 182-90.

Clarke, L. 1995. Family care and changing family structure: bad news for the elderly? In Allen, I. and Perkins, E. (eds), The Future of Family Care for Older People. HMSO, London, 19-49.

Colombo, F., Llena-Nozal, A., Mercier, J. and Tjadens, F. 2011 a. Help Wanted? Providing and Paying for Long-term Care. OECD Policy Brief. Available online at http://www.oecd.org/els/health-systems/helpwantedprovidingandpayingforlongtermcare.htm [Accessed June 2013].

Colombo, F., Llena-Nozal, A., Mercier, J. and Tjadens, F. 2011 b. Help Wanted? Providing and Paying for Long-term Care. OECD, Paris. 
Comas-Herrera, A., Wittenberg, R., Gori, C., Costa-i-Font, J., di Maio, A., Patxot, C., Pickard, L., Pozzi, A. and Rothgang, H. 2006. Future long-term care expenditure in Germany, Spain, Italy and the United Kingdom. Ageing E Society, 26, 2, $285^{-302 .}$

Comas-Herrera, A., Wittenberg, R. and Pickard, L. 2010. The long road to universalism? Recent development in the financing of long-term care in England. Social Policy E Administration, 44, 4, 375-91.

Comas-Herrera, A., Wittenberg, R. and Pickard, L. 2011 . From commission to commission: financing long-term care in England. In Courbage, C. and Costa-Font, J. (eds), Financing Long-term Care. Palgrave Macmillan, Basingstoke, UK, ${ }^{1}{ }^{1-69}$.

Commission on Funding of Care and Support (CFCS) 2011. Fairer Care Funding. Volume I, The Report of the Commission on Funding of Care and Support, Commission on Funding of Care and Support, London.

Davies, A. and Newman, S. 2011 . A systematic review to examine the effect of telecare for people with social care needs on outcomes for their informal carers. Paper presented at the International Congress on Telehealth and Telecare, The King's Fund, 1-3 March, London.

Evandrou, M. 2000. Social inequalities in later life: the socio-economic position of older people from ethnic minority groups in Britain. Population Trends, 101, 1 1-19.

Evandrou, M. and Glaser, K. 2002. Changing economic and social roles: the experience of four cohorts of mid-life individuals in Britain, $1985^{-2000 .}$ Population Trends, 110, 19-30.

Gaymu, J., Ekamper, P. and Beets, G. 2007. Who will be caring for Europe's dependent elders in 2030? Population, 62, 4, 675-706.

Gaymu, J., Festy, P., Poulain, M. and Beets, G. (eds) 2008. Future Elderly Living Conditions in Europe. Institut National d'Études Démographiques, Paris.

Geerts, J., Willemé, P., Pickard, L., King, D., Comas-Herrera, A., Wittwer, J., Goltz, A., Mot, E., Schultz, E., Sowa, A. and Vegas, R. 201 2. Projections of Use and Supply of Longterm Care in Europe: Policy Implications. Assessing Needs of Care in European Nations (ANCIEN) Policy Brief. Available online at http://www.ancien-longtermcare.eu/ policy_briefs [Accessed June 2013].

Glaser, K. and Grundy, E. 2002. Class, caring and disability: evidence from the British Retirement Survey. Ageing $\mathcal{E}^{2}$ Society, 22, 3, 325-42.

Glaser, K., Tomassini, C., Racioppi, F. and Stuchbury, R. 2006. Marital disruption and loss of support in later life: a longitudinal study of the United Kingdom. European Journal of Ageing, 3, 4, 207-16.

Glendinning, C. 1992. The Costs of Informal Care: Looking Inside the Household. HMSO, London.

Grundy, E. 200o. Co-residence of mid-life children with their elderly parents in England and Wales: changes between 1981 and 1991. Population Studies, 54, 2, 193-206.

Haberkern, F. K., Schmid, T., Neuberger, F. and Grignon, M. 201 2. The role of the elderly as providers and recipients of care. In OECD. The Future of Families to 2030. OECD Publishing, Paris, 189-257.

Health and Social Care Information Centre 2010. Survey of Carers in Households 2009/Io. NHS Health and Social Care Information Centre, Leeds, UK.

Heitmueller, A. 2007. The chicken or the egg? Endogeneity in labour market participation of informal carers in England. Journal of Health Economics, 26, 3, $53^{6-59}$.

Her Majesty's Government (HMG). 201 o. Building the National Care Service. CM 7854, The Stationery Office, London. 
Her Majesty's Government (HMG). 201 2. Caring for Our Future. Progress Report on Funding Reform, CM 8381, The Stationery Office, London.

Hirst, M. 1999. Informal care-giving in the life course. Social Policy Research Unit (SPRU) Working Paper DH 1633, SPRU, University of York, York, UK.

Hirst, M. 2001. Trends in informal care in Great Britain during the 1990s. Health and Social Care in the Community, 9, 6, 348-57.

Karlsson, M., Mayhew, L., Plumb, R. and Rickaysen, B. 2006. Future costs for long-term care. Cost projections for long-term care for older people in the United Kingdom. Health Policy, 75, 2, $187-213$.

Kemper, P. 1992. The use of formal and informal home care by the disabled elderly. Health Services Research, 27, 4, 441-51.

King, D. and Pickard, L. 2013. When is a carer's employment at risk? Longitudinal analysis of unpaid care and employment in midlife in England. Health and Social Care in the Community, $\mathbf{2 1}, 3,303^{-1} 4$.

Kraus, M., Czypionka, T., Riedel, M., Mot, E. and Willemé, P. 201 1. How European Nations Care for Their Elderly. A New Typology of Long-term Care Systems. Assessing Needs of Care in European Nations (ANCIEN) Policy Brief. Available online at http://www.ancien-longtermcare.eu/policy_briefs [Accessed June 2013].

Leontaridi, R. and Bell, D. 2001. Informal care of the elderly in Scotland and the UK. In Machin, D. and McShane, D. (eds), Providing Free Personal Care for Older People: Research Commissioned to Inform the Work of the Care Development Group. Scottish Executive Central Research Unit, Edinburgh, UK, $207-38$.

Maher, J. and Green, H. 2002. Carers 20oo. The Stationery Office, London.

Malley, J., Hancock, R., Murphy, M., Adams, J., Wittenberg, R., Comas-Herrera, A., Curry, C., King, D., James, S., Morciano, M. and Pickard, L. 2011. The effect of lengthening life expectancy on future pension and long-term care expenditure in England, 2007 to 2032. Health Statistics Quarterly, 52, 33-61.

Murphy, M. and Grundy, E. 2003. Mothers with living children and children with living mothers: the role of fertility and mortality in the period $19^{11-20} 5^{\circ}$. Population Trends, $112,3^{6-44}$.

Murphy, M., Martikainen, P. and Pennec, S. 20o6. Demographic change and the supply of potential family supporters in Britain, Finland and France in the period 1911-2050. European Journal of Population, 22, 3, 219-40.

Office for National Statistics (ONS) 2008. National Population Projections, 2oo6-based. Palgrave Macmillan, Basingstoke, UK.

Office for National Statistics (ONS) 2009. 20o6-based marital status and cohabitation projections for England and Wales. Population Trends, 136, $112-20$.

Parker, G. 1993. Informal care of older people in Great Britain: the $198_{5}$ General Household Survey. In Twigg, J. (ed.), Informal Care in Europe. Social Policy Research Unit, University of York, York, UK, $15^{1-69}$.

Parker, G. 1998. Trends in caring 1985-1995. In Rowlands, O. (ed.), Informal Carers. The Stationery Office, London, 39-48.

Parker, G. and Lawton, D. 1994. Different Types of Care, Different Types of Carer. Evidence from the General Household Survey. HMSO, London.

Pickard, L. 2007. Unpaid care and the family. In Smallwood, S. and Wilson, B. (eds), Focus on Families. 2007 edition, Office for National Statistics, London, 20-34.

Pickard, L. 2008. Informal Care for Older People Provided by Their Adult Children: Projections of Supply and Demand to $204 \mathrm{I}$ in England. Personal Social Services Research Unit (PSSRU) Discussion Paper $25^{1} 5$, PSSRU, London School of Economics and Political Science. Available online at http://www.pssru.ac.uk/archive/pdf/ dp2515.pdf [Accessed June 2013]. 
Pickard, L. 2009. No end of care. Informal care for older parents in Britain between 1985 and 2000. PhD thesis, London School of Economics and Political Science, London. Available online at http://etheses.lse.ac.uk/323/ [Accessed June 2013].

Pickard, L. 2012. Substitution between formal and informal care: a 'natural experiment' in social policy in Britain between 1985 and 2000. Ageing Ev Society, 32, 7, $1147-75$.

Pickard, L., Wittenberg, R., Comas-Herrera, A., Davies, B. and Darton, R. 2000. Relying on informal care in the new century? Informal care for elderly people in England to 2031. Ageing E Society, 2o, 6, 745-72.

Pickard, L., Wittenberg, R., Comas-Herrera, A., King, D. and Malley, J. 201 2. Mapping the future of family care: receipt of informal care by older people with disabilities in England to 2032. Social Policy and Society, 11, 4, 533-45.

Qureshi, H. and Walker, A. 1989. The Caring Relationship. Elderly People and Their Families. Macmillan, Basingstoke, UK.

Richards, E., Wilsdon, T. and Lyons, S. 1996. Paying for Long-term Care. Institute for Public Policy Research, London.

Royal Commission on Long Term Care 1999. With Respect to Old Age: Long Term Care-Rights and Responsibilities. Cm 4192-1, The Stationery Office, London.

Soldo, B. 1996. Cross pressures on middle-aged adults: a broader view. Journals of Gerontology: Social Sciences, 51B, 6, S27 1-3.

United Nations 2002. World Population Ageing: 1950-2050. Department of Economic and Social Affairs, Population Division, United Nations, New York.

Wittenberg, R., Comas-Herrera, A., King, D., Malley, J., Pickard, L. and Darton, R. 2006. Future Demand for Long-term Care, 2002-204I: Projections of Demand for Long-term Care for Older People in England. Personal Social Services Research Unit Discussion Paper 233o. Available online at http://www.pssru.ac.uk/pdf/dp233o. pdf [Accessed June 2013].

Wittenberg, R., Pickard, L., Comas-Herrera, A., Davies, B. and Darton, R. 2001. Demand for long-term care for older people in England to 2031. Health Statistics Quarterly, 12, $5^{-17}$.

Young, H., Grundy, E. and Kalogirou, S. 2005. Who cares? Geographic variations in unpaid caregiving in England and Wales: evidence from the 2001 Census. Population Trends, 120, 23-34.

Accepted I July 20I3; first published online 22 August $2 \mathrm{OI}_{3}$

Address for correspondence:

Linda Pickard, London School of Economics \& Political Science -

LSE Health and Social Care,

Houghton Street, London WC2A 2AE, UK.

E-mail: 1.m.pickard@1se.ac.uk 